\title{
O MERCADO DE TRABALHO EM LOGÍSTICA PARA O SURDO: POSSIBILIDADES E DESAFIOS
}

\author{
Elizangela de Jesus Melo \\ FATEC-MOGI DAS CRUZES - CEETEPS, elizangela.melo@fatec.sp.gov.br \\ Jenifer Dias Torres \\ FATEC-MOGI DAS CRUZES - CEETEPS, jenifer.torres@fatec.sp.gov.br \\ Natália Ferreira Marques \\ FATEC-MOGI DAS CRUZES - CEETEPS, natalia.marques2@fatec.sp.gov.br \\ Marina Codo Andrade Teixeira \\ FATEC-MOGI DAS CRUZES - CEETEPS, marina.teixeira@fatec.sp.gov.br \\ Rafael de Arruda Bueno José Miguel \\ FATEC-MOGI DAS CRUZES - CEETEPS, rafael.miguel01@fatec.sp.gov.br
}

\begin{abstract}
RESUMO
Mesmo diante das leis vigentes, o surdo enfrenta dificuldades de adentrar e permanecer no mercado de trabalho, apesar das organizações terem uma atenção especial à necessidade de oportunidades inclusivas. O desenvolvimento do presente artigo possibilita uma análise referente ao mercado ocupacional logístico para profissionais surdos. Através desse estudo foi possível reconhecer as dificuldades de profissionalização do surdo e as adequações necessárias para incluí-los no ambiente empresarial logístico. A metodologia de pesquisa utilizada é de cunho exploratório e de caráter qualitativo, o que permitiu a realização de busca por oportunidades disponíveis na área logística e por esta concluiu-se que grande parte das vagas ofertadas para surdos ainda são de baixa complexidade e há limitações para seu crescimento profissional e promoções de cargo. Destaca-se ainda a grande importância da Língua Brasileira de Sinais (Libras) para a devida comunicação e integração do surdo nas organizações.
\end{abstract}

Palavras-Chave: Surdo. Libras. Logística. Mercado de Trabalho.

\begin{abstract}
Even in the face of current laws, the deaf face difficulties to enter and remain in the labor market, although the associations pay special attention to the need for inclusive opportunities. The development of this article allows an analysis regarding the logistical occupational market for deaf professionals. All of this study was able to be recognized as difficulties in professionalizing the deaf and necessary adjustments to include them in the logistical business environment. The research methodology used is exploratory and qualitative, which accomplishes search for opportunities available in the logistics and through this, it was concluded that a large part of the vacancies offered to the deaf are still of low complexity and there are limitations for your professional growth and promotions. It is also worth mentioning the great importance of the Brazilian Sign Language (Libras) for the proper communication and integration of the deaf in the associations.
\end{abstract}

Key-words: Deaf. Libras. Logistics. Labor Market. 


\section{INTRODUÇÃO}

O presente artigo tem por finalidade estudar a empregabilidade de pessoas surdas no ramo da logística e os desafios e oportunidades que entornam o tema.

Em 6 de julho de 2015 foi instituído o Estatuto da Pessoa com Deficiência, pela lei federal no 13.146, mais conhecida como Lei Brasileira de Inclusão, sancionada pela expresidente Dilma Rousseff, na qual são expressos uma gama de princípios, concepções e direitos em relação às pessoas com deficiência, entre eles o direito ao estudo e ao trabalho, assegurado pelo Estado, sociedade, comunidade e família para com estes

Esse documento comunga com o que foi disposto em nossa Lei Maior (BRASIL, 1988) em relação a garantia de direitos a todas as pessoas: surdos, ouvintes, homens, mulheres, pretos, brancos, indígenas, andantes, cadeirantes, pessoas com deficiência visual, pessoas com deficiência física, pessoas com deficiência intelectual, pessoas com autismo, pessoas com síndrome de Down, entre outros).

De posse da consciência desses direitos, tem-se que o objeto de estudo desse trabalho envolverá um recorte sobre as possibilidades e desafios dos surdos (ou pessoas Surdas) no mercado de trabalho em logística. Como sujeitos de direito, eles têm buscado sua inserção, permanência e crescimento no mundo do trabalho e levam consigo suas formações, potencialidades e singularidades. Desse modo, tem-se a seguinte questão mestra da pesquisa: com o estudo de algumas publicações e dedicando-se à observação do que é próprio da área da logística quando na inserção de um empregado surdo, há mercado de trabalho disponível para esse público (os surdos)?

A justificativa da escolha desse público (os surdos) como alvo da pesquisa se deu por meio do contato com a disciplina de Libras, presente na graduação de Gestão em Recursos Humanos. Os primeiros passos em direção ao aprendizado dessa língua, as dinâmicas, leituras e discussões vivenciadas nas aulas despertaram o interesse em aprofundar o estudo sobre as singularidades dessa comunidade, mais especificamente, de sua relação laboral com a área de logística.

A Libras tem sido introduzida gradualmente em vários canais de comunicação ou espaços sociais, podendo ser encontrada, por exemplo, nas esferas religiosa, artística e televisiva, ampliando assim um pouco mais - mais ainda com muitas demandas - um mundo de informações e comunicação por meio da acessibilidade. Além disso, contribuindo com o 
entendimento de que as pessoas surdas têm uma língua própria, diferente e importante para si, a qual anula a deficiência e constitui esse grupo como uma minoria linguística e desprendido de uma visão de anormalidade (SKLIAR, 1997).

Diante do contexto brevemente exposto, despertou-se a curiosidade no mercado de trabalho em logística para profissionais surdos que adentrem a área e como se daria sua inclusão nesse ambiente.

É oportuno comentar que, as autoras, graduandas em Gestão de Recursos Humanos, por serem companheiras de turno com o curso de Gestão em Logística, observaram que a oportunidade de contato com a Libras e a comunidade surda não era a mesma para ambos os cursos. Diferentemente do curso de Gestão de Recurso Humanos, o curso de Gestão em Logística não possui nenhuma disciplina correlata.

A metodologia de pesquisa utilizada é de cunho exploratória, de caráter qualitativo, sendo a análise dos dados baseada na análise textual discursiva, a fim de tratar o ambiente empresarial de logística e suas características, assim como expor as questões da formação do surdo para inserção no trabalho.

A análise qualitativa depende de muitos fatores, tais como a natureza dos dados coletados, a extensão da amostra, os instrumentos de pesquisa e os pressupostos teóricos que nortearam a investigação. Pode-se, no entanto, definir esse processo como uma sequência de atividades, que envolve a redução dos dados, a categorização desses dados, sua interpretação e a redação do relatório (GIL, 2002, p.133).

Por se enquadrar numa pesquisa exploratória, o presente trabalho está ancorado num entendimento marcado pela flexibilidade investigativa dos mais variados aspectos do objeto estudado, bem como pelo refinamento das ideias cunhado com o intuito de proporcionar ao leitor a familiarização com o tema discutido (GIL, 2002).

Para atingir o objetivo da pesquisa foi realizado um profundo estudo teórico referente ao tema, compreendendo não só a comunidade surda, como também a área de logística. Após a pesquisa bibliográfica, foram analisados aspectos coerentes com a realidade dos surdos e as necessidades de adequação das organizações que recebam um surdo em seu quadro de funcionários. 


\section{EMBASAMENTO TEÓRICO}

\subsection{O direito à inserção no mercado de trabalho}

"O trabalho dignifica o homem" (WEBER, 1920, 2020), como descreve o sociólogo Max Weber em sua obra "A ética protestante e o espírito do capitalismo". Desde os primórdios da vida humana e da vida social, o homem trabalhador é tido como digno e honrado e apesar de erroneamente ser considerado um mandamento bíblico, o ditado tornado tão popular não foge dos princípios deixados nas sagradas escrituras. Num exceto bastante conhecido: “Do suor do teu rosto comerás o teu pão" (BÍBLIA, Gênesis, 3,19), retrata o momento em que Deus ordena para que Adão e Eva comecem a trabalhar para seu sustento e de sua família, logo após terem sido expulsos do Jardim do Éden.

Os primeiros homens catalogados tinham como fonte de sobrevivência a caça e posteriormente o cultivo. A partir desse trabalho árduo e braçal, enveredaram evoluções que os ajudaram na adaptação de seu habitat até chegarem ao que se denomina hoje Homo Sapiens. Independente das crenças ou linhas científicas, que cada ser individual segue, o fato é que o trabalho é uma atividade tipicamente humana, sendo um conjunto de ações produtivas e/ou criativas que este usa para atingir determinado fim. Nesse entendimento, o ser humano não seria escravo de suas tarefas, mas livre para buscar seus objetivos por meio de processos práticos.

Na Constituição Federal de 1988, é garantido o direito ao trabalho. $\mathrm{O}$ artigo 1으, incisos III e IV, abordam, respectivamente, "a dignidade da pessoa humana" e "os valores do trabalho e a livre iniciativa". Logo adiante, no 6ำ artigo, tem-se que "são direitos sociais a educação, a saúde, a alimentação, o trabalho, a moradia, o transporte, o lazer, a segurança, a previdência social, a proteção à maternidade e à infância, a assistência aos desamparados, na forma desta Constituição" (BRASIL, 1988 - grifo nosso).

A Lei Maior, em suas disposições respectivas ao trabalho, afirma que "é livre o exercício de qualquer trabalho, ofício ou profissão, atendidas as qualificações profissionais que a lei estabelecer", ou seja, são deliberações propícias a todos os cidadãos e cidadãs, quer seja ouvinte ou surdo, falante de português ou de Libras. 
Outra normativa jurídica de grande relevância é a Lei Federal no 8.213/91, que, entre muitos pontos, dispõe sobre a obrigatoriedade da contratação de pessoas com deficiência por meio de cotas, a saber:

Art. 93. A empresa com 100 (cem) ou mais empregados está obrigada a preencher de $2 \%$ (dois por cento) a $5 \%$ (cinco por cento) dos seus cargos com beneficiários reabilitados ou pessoas portadoras de deficiência, habilitadas, na seguinte proporção:

$\begin{array}{ll}\text { I - até } 200 \text { empregados_ } & 2 \% ; \\ \text { II - de } 201 \text { a } 500 & 3 \% ; \\ \text { III - de } 501 \text { a } 1.000 & 4 \% ; \\ \text { IV - de } 1.001 \text { em diante } & 5 \% .\end{array}$

(BRASIL, 1991)

Passados alguns anos, em 2015, quando foi instituída a Lei Federal no 13.146, conhecida como Lei Brasileira de Inclusão - LBI, mais uma vez, contudo, agora de forma específica e propositiva, há o destaque em torno da garantia de direitos ao trabalho para esse público, a saber: "Art. 34. A pessoa com deficiência tem direito ao trabalho de sua livre escolha e aceitação, em ambiente acessível e inclusivo, em igualdade de oportunidades com as demais pessoas" (BRASIL, 2015 - grifos nossos).

Diante dessas normativas legais e das reivindicações da sociedade civil e movimentos de pessoas com deficiência, um dos grandes desafios das empresas passou a ser o de incorporar esses profissionais nas organizações. O discurso da inclusão e da acessibilidade e as proposições legais para a inserção - ainda que obrigatória - dos trabalhadores com deficiência passaria, ainda que de forma paulatina, ser tarefa a ser executada por muitos gestores.

Apesar da luta da sociedade civil e dos coletivos de pessoas com deficiência, em 2019, foi recebida na Câmara dos Deputados uma proposta do Governo Federal (PL 6.159/19), que em suma, desobrigariam e flexibilizariam as empresas quanto ao cumprimento da normativa de cotas de trabalhadores com deficiência pelo aval e pagamento de uma contribuição à União (algo em torno de dois salários-mínimos mensais) a ser destinada a programas de reabilitação física e habilitação profissional. Além disso, permitiria a união de duas ou mais empresas para alcançar o coeficiente de contratação descrito em lei (MACHADO, 2019).

No entanto, diante dessa proposta, questiona-se quais seriam as garantias de que a flexibilização da lei iria favorecer de fato os colaboradores com deficiência e não somente as 
empresas. De qualquer forma, sabe-se que o projeto não ganhou o regime de urgência constitucional por necessidade de discussão mais aprofundada (LINO; WELLICHAN, 2019).

\subsection{Surdos, quem são eles?}

Considera-se surdo o indivíduo que, "por perda auditiva, compreende e interage com o mundo por meio de experiências visuais, manifestando sua cultura principalmente pelo uso da Língua Brasileira de Sinais - Libras" (BRASIL, 2005).

Gesser (2009) descreve o estranhamento pelo qual muitas pessoas ouvintes, alheias à discussão sobre a surdez, têm em relação ao uso da palavra "surdo", uma vez que pode imprimir uma ideia pejorativa ou de preconceito, enquanto o termo deficiente auditivo parece-lhes ser mais politicamente correto.

Em relação a essa discussão, enquanto surda, Laborrit (apud GESSER, 2009) afirma: “Recuso-me a ser considerada excepcional, deficiente. Não sou. Sou Surda. Para mim a língua de sinais corresponde à minha voz, meus olhos são meus ouvidos. Sinceramente nada me falta, é a sociedade que me torna excepcional". Mesmo que sem intenção direta a nomenclatura "deficiente" não soa bem, tão pouco representa os surdos.

A deficiência é uma marca que historicamente não tem pertencido aos surdos. Essa marca sugere autorrepresentações, políticas e objetivos não familiares ao grupo. Quando os surdos discutem sua surdez, usam termos profundamente relacionados com sua língua, seu passado, e sua comunidade (PADDEN \& HUMPHRIES apud GESSER, 2009, p. 46).

Pode-se classificar os surdos em dois grupos predominantes: os surdos oralizados e os surdos sinalizadores. Bieging, Busarello e Ulbricht (2013, p.75) descrevem que surdos oralizados "são aqueles que, em geral, não utilizam de língua de sinais para se comunicar, mas sim de uma língua oral, como o português para o caso do Brasil". Enquanto que os surdos sinalizadores são as "pessoas surdas que fazem uso de uma língua visual-espacial ou gestual, que é adequada a sua capacidade de expressão e, para o caso brasileiro, utilizam a Libras".

A Lei Federal no 10.436/2002, reconhece a Língua Brasileira de Sinais (Libras) como sistema linguístico de transmissão de ideias, fatos e emoções, assim como um meio legal de comunicação e expressão inerente à comunidade surda. Bastante diferente do histórico de proibição do uso da língua de sinais pelos surdos:

Durante quase cem anos as línguas de sinais foram proibidas nas escolas para surdos, sendo usadas de forma escondida nas associações e em pontos de encontro dos Surdos. Nos últimos anos, no entanto, com a mudança na concepção de surdez, e como resultado das lutas dos Surdos, elas vêm 
assumindo um papel importante em todos os espaços, o que tem resultado em ampliação significativa de seu vocabulário (CHOI et al., 2011, p. 20).

Segundo Gesser (2009), é incorreto o pensamento de que Libras se limita a mímica ou gestos soltos, pois ela é constituída de uma estrutura linguística e gramatical própria, o que permite aos que utilizam dessa língua, discutir sobre qualquer assunto. Outra característica importante diz respeito a sua não universalidade, já que cada país possui sua própria língua de sinais, sem falar nas diferenças lexicais que mudam de acordo com a cultura de cada região.

A comunicação não deve ser vista como impasse para o desenvolvimento do indivíduo, seja em seu meio familiar e social, como no educacional e profissional. A Libras é o elemento chave que desmistifica a premissa de que o surdo possui uma deficiência comunicativa, provando apenas que sua comunicação se enquadra numa língua de sinais única que merece reconhecimento social - visto que o reconhecimento legal e acadêmico ela já possui - e estudo, assim como qualquer língua seja nacional ou estrangeira.

\subsection{Qualificação profissional do surdo}

Para que o profissional surdo seja inserido no mercado de trabalho, sua preparação começa na educação e em sua qualificação. Sendo a base fundamental para a inclusão como afirma Loxe et al (2019), "a educação tem o objetivo de integrar a pessoa surda às condições de participação efetiva e envolvimento na vida produtiva social e tem papel de garantir o acesso inclusivo na sociedade".

Adotada na maioria dos países, a Declaração de Salamanca, que inspirou a elaboração da Lei de Diretrizes e Bases da Educação do Brasil, disserta sobre os desafios para inclusão de minorias e defende que seus direitos sociais entrem na pauta de diversos âmbitos, inclusive o educacional.

Pensando no acesso ao ensino superior, faz-se necessário salientar a Lei Federal no 13.409/2016, que disserta sobre as alterações da Lei Federal no 12.711/2012, estabelece a reserva de vagas para pessoas com deficiência (o mesmo vale para pessoas que se autodeclarem pretas, pardas ou indígenas) em igual proporção ao percentual da população de pessoas com deficiência "[...] na população da unidade da Federação onde está instalada a instituição, segundo o último censo da Fundação Instituto Brasileiro de Geografia e Estatística - IBGE" (BRASIL, 2016). 
A condição de surdo não deve ser colocada como empecilho. Como afirma Viana (2010) citado por Loxe at al (2019), "elevar a escolaridade e a qualificação profissional, ao invés de usar isto como desculpa para não-contratação dos deficientes (sic), inclusive o surdo, é papel da sociedade como um todo, incluindo principalmente empresas e governantes". Assim, a responsabilidade pela fomentação de programas que visem uma melhor qualificação profissional dos surdos e dos outros grupos minoritários, deve ser do poder público e de toda a sociedade.

\subsection{O surdo diante do mercado de trabalho na logística}

A logística permeia quase todos os aspectos do nosso cotidiano e, sem ela, as mercadorias, os produtos e os serviços que damos como certos não chegariam até nós. Observando as constantes evoluções tecnológicas mundiais, o perfil do profissional de logística buscado pelas empresas não é mais o de alguém para carregar ou descarregar produtos, mas de quem pense em soluções estratégicas que agilizem os diversos encalços da atividade (GRANT, 2013).

O preconceito e a imposição de limitações sobre os surdos e pessoas com deficiência tem sido ainda pouco discutido pela sociedade. Como efeito disto, surge a grande dificuldade para inserção no mercado de trabalho, o que afeta também sua vida familiar e social (ANTUNES; ARCARI; PURIFICAÇÃO, 2020).

Tanto na iniciativa pública, quanto na privada não há preparo suficiente para a inserção de um surdo no ambiente de trabalho formal. A falta de incentivo governamental tanto para a educação, quanto para a inserção no mercado de trabalho, influencia em sua contratação e o deixa longe do empregador, uma vez que, em alguns casos, o surdo nem sempre está preparado academicamente para o que é exigido na organização, que por sua vez nem sempre está disposta a empregá-lo pelo desconhecimento acerca das singularidades desse candidato (LOXE et al., 2019).

Segundo dados da Organização das Nações Unidas (ONU), 10\% da população brasileira apresenta algum tipo de deficiência, ou seja, são cerca de 16 milhões de pessoas com deficiências e destes, há 1,3\% de pessoas surdas (LINO; WELLICHAN, 2019).

De acordo com o Relatório Anual de Informações Sociais (RAIS), de 2019, ao demonstrar a evolução da distribuição de estoque de empregos formais por tipo de deficiência, em 2019 o estoque de vagas para pessoas com algum grau de perda auditiva é de 
17,74\%. Se comparado ao começo da década, observamos uma queda brusca, já que em 2010 a porcentagem estava em 22,49\%. (RAIS, 2019).

Antunes, Arcari e Purificação (2020), dissertam que "a inclusão do surdo no mercado de trabalho é um dos fatos que mais suscita preocupações, pois é perceptível a dificuldade de acessibilidade física e de meios de comunicação para que o indivíduo em questão necessita para desenvolver sua carreira [...]". Todas essas complicações para sua inserção em um emprego formal podem afetar diretamente suas perspectivas no que tangem seu crescimento profissional.

A pesquisa de Borges et al. (2020) feita com 6 empresas do Centro-Oeste do Brasil, comprovou o despreparo para a recepção de trabalhadores surdos. Analisando os pesquisados para cargos de empacotador e despachante de mercadorias, foi observado que as organizações na maioria das vezes estão "preocupadas apenas em preencher as cotas e não estão atentas às necessidades do trabalhador", nesse caso do trabalhador surdo. Tais atitudes saem do contexto da própria responsabilidade social empresarial necessária, que Loxe et al. (2019) define como a capacidade que as organizações desenvolvem de ouvir, reter compreensão e satisfazer as expectativas de seus diversos públicos.

\section{DESENVOLVIMENTO DA TEMÁTICA}

A presente pesquisa foi embasada em metodologia exploratória, de caráter qualitativo, utilizando-se de pesquisas em materiais científicos como artigos e livros a fim de determinar um perfil das necessidades de adequações para a inserção do empregado surdo no mercado de trabalho de logística. Para compreender o mercado de trabalho em logística para surdos foi realizada uma busca por vagas da área para candidatos surdos no site INFOJOBS. A busca foi realizada entre os dias 3 e 6 de maio de 2021, sendo encontradas 21 vagas concernentes ao propósito do presente estudo. A busca foi feita com as palavras-chave: surdo, logística, auditivo e PcD.

\section{RESULTADOS E DISCUSSÃO}

De acordo com a legislação trabalhista, para que a pessoa com deficiência possa fazer parte da rotina da organização é necessário que a alta administração promova e coloque em prática todas as ações cabíveis que contribuam para esse fim. 
As autoridades competentes deverão adotar medidas para proporcionar e avaliar os serviços de orientação e formação profissional, colocação, emprego e outros semelhantes, a fim de que as pessoas deficientes possam obter e conservar o emprego e progredir no mesmo; sempre que for possível e adequado serão utilizados os serviços existentes para os trabalhadores em geral, com adaptações necessárias (ANAMT, 2007, p. 59).

Predominam nas organizações a falta de acessibilidade e de adequação das condições de trabalho, delegando às pessoas com deficiência dificuldade de mobilidade e difícil ascensão entre as funções, segregação em setores específicos das empresas, não compreensão do trabalho, contratação pelas empresas visando apenas melhorar o seu marketing institucional, e outras apenas pela determinação legal (ABREU; MORAES apud LINO; WELLICHAN, 2019). Entende-se que para que a inserção do surdo no trabalho aconteça plenamente, é necessário que ocorra mudanças de paradigmas, isto porque as empresas precisam desenvolver ações que visem a adequação ou modificações do seu ambiente físico, funcional, social e atitudinal.

\subsection{0 perfil de logística assumido por um surdo}

O estudo de Lino e Wellichan (2019) explica que para que uma pessoa com deficiência desenvolva suas funções com qualidade, "medidas que envolvam todo o entorno dela precisam ser consideradas e incluídas como parte do processo, caso contrário, trata-se apenas de um cumprimento de cotas superficial" (p. 118). A repositora surda entrevistada no estudo de caso dos autores citados conta que suas atividades foram ensinadas pela supervisora responsável do setor, por meio de gestos e apontamentos, ou seja, não havia uma comunicação por meio de uma língua de fato, no caso a Libras, mas sim da mescla de uma forma bastante rudimentar e rasa. Além disso, ela comenta que nunca havia sido convidada a participar de cursos oferecidos pela empresa. Diante disso, é possível inferir que, certamente, o mesmo deveria ocorrer nos momentos de reuniões, demais formações menores, informes triviais do cotidiano entre outros.

Indo de encontro ao pensamento de Grant (2013), de que o perfil do profissional logístico almejado seja o de alguém que possua pensamento estratégico que agilizem os encalços da atividade, é possível afirmar que o surdo também se enquadra nesse perfil de modo que é passível de constante aprendizagem e evolução cognitiva e linguística, capaz de utilizar seu pensamento estratégico apesar das mais diversas representações de quem o cerca, por vezes, banhada de preconceitos e concepções limitantes (ANTUNES; ARCARI; PURIFICAÇÃO, 2020) que, via de regra, tendem a gerar entraves na inserção e permanência 
nas empresas ou, uma vez, já empregados, crescimento ou mobilidade (promoção) de cargos no ambiente de trabalho.

O fato de a pessoa ser surda não lhe imputa nenhum problema cognitivo, se o que the for ensinado for transmitido com as mesmas condições e respeito ofertado a uma pessoa ouvinte. Dito de outro modo, se uma pessoa ouvinte falante de português recebeu as orientações para determina função em sua primeira língua ou em sua língua de conforto, ou seja, o português oral, da mesma forma, a pessoa surda deverá receber as informações e orientações por meio de sua primeira língua ou em sua língua de conforto, a saber, a Libras (BRASIL, 2002; 2005), sem que com isso tenha nenhuma dificuldade ou hiato na compreensão (LACERDA apud FRANCO, 2019).

Levando em conta um cargo de operação, como o de repositor de estoques, e um cargo estratégico dentro da logística, como o de analista de logística, a barreira de crescimento do profissional surdo repousaria na escassez de oferta de oportunidades de crescimento, nas representações limitantes em relação ao surdo por parte das empresas ou até mesmo por falta de formação específica do trabalhador apesar de ter totalmente preservada suas condições cognitivas que lhe permitiriam tal mobilidade de função (LINO; WELLICHAN, 2019).

Situação semelhante aconteceu com a repositora surda, de 32 anos, entrevistada por Lino e Wellichan (2019) em que apesar de ter manifestado seu desejo de mobilidade para uma função administrativa, não logrou sucesso por falta de acessibilidade nos programas de formação e capacitação da empresa, os quais lhe eram negados. Tendo sugerido um projeto de inclusão de cursos de Libras na empresa, a aceitação não foi favorável.

\subsection{Adequações necessárias para acolhimento do surdo no ambiente organizacional}

As medidas laborais tomadas no ambiente logístico estudado pelos autores inicialmente indicados, constataram a necessidade da implantação de ações e elementos físicos estruturais como um sinal luminoso para início ou fim da jornada de trabalho, bem como para alertar em caso de incêndio ou outros sinistros e constante manutenção destes aparelhos e equipamentos para que estejam integralmente disponíveis no processo de inclusão diária do surdo; colocação de intérpretes de Libras nos espaços de formação, tais como reuniões, planejamentos, feedbacks entre chefia e empregado; oferta de curso de Libras para os demais colaboradores a fim de promover a comunicação entre surdos e ouvintes. 
Com as adequações básicas citadas acima, demonstrando a responsabilidade social organizacional, a empresa se colocará num caminho mais inclusivo e de respeito à diversidade humana, de modo a permitir que o profissional surdo exerça suas funções em cargos na área de logística de uma forma mais eficaz e produtiva.

Após análise e avaliação das descrições de cargos aqui propostos, identificamos que a predisposição e alguns investimentos por parte da organização contribuem para a inserção e acessibilidade do surdo na realização de tal tarefa. As adequações citadas por Lino e Wellichan (2019), onde sugere a sinalização tanto sonora como visual, para alarmes, início e término da jornada; utilização de aplicativos que facilitam a comunicação; intérprete de libras como forma de acessibilidade para que os trabalhadores possam acompanhar os cursos e palestras da organização, devem integrar esses investimentos.

\subsection{Mercado de trabalho na logística para Surdos}

Lino (2015), apresenta algumas características que determinam o nível da perda auditiva que podem identificar as possibilidades do ser humano na identificação do som, conforme Quadro 1 a seguir.

Quadro 1. Níveis de perda auditiva

\begin{tabular}{|l|l|}
\hline \multicolumn{1}{|c|}{ Perda Auditiva } & \multicolumn{1}{c|}{ Características } \\
\hline $\begin{array}{l}\text { Surdez leve: } 25 \text { a } 40 \mathrm{~dB} \\
\text { Surdez moderada: } 41 \mathrm{a} 70 \mathrm{~dB}\end{array}$ & $\begin{array}{l}\text { Apresenta perda auditiva, dificultando, mas não impedindo que o } \\
\text { indivíduo se expresse oralmente e perceba a voz humana com ou sem o } \\
\text { uso da AASI (Aparelho de Amplificação Sonora Individual). }\end{array}$ \\
\hline $\begin{array}{l}\text { Surdez severa: } 71 \text { a } 90 \mathrm{~dB} \\
\text { Surdez profunda: acima de } 90 \mathrm{~dB}\end{array}$ & $\begin{array}{l}\text { Apresenta perda auditiva impedindo o indivíduo de compreender a voz } \\
\text { humana, com ou sem aparelho auditivo, além da aquisição natural do } \\
\text { código linguístico oral, em que os alunos necessitarão de métodos e } \\
\text { recursos didáticos adequados. }\end{array}$ \\
\hline
\end{tabular}

Fonte: Adaptada de Lino (2015, p. 23)

Após buscas em 21 anúncios encontrados no site de vagas INFOJOBS, colocando um filtro específico para pessoas com deficiência e onde incluía-se candidatos surdos, chegou-se ao seguinte resultado:

- 8 anúncios de vagas corresponderam ao nível de operador e aceitam candidatos de todos os graus de surdez, desde leve à profunda;

- 7 correspondem ao cargo de auxiliar logístico: 5 destas considerando do nível leve ao profundo de perda auditiva, 1 apenas surdez moderada e 1 apenas acentuada e moderada; 
- 3 anúncios corresponderam ao nível de analista da área logística e aceitavam candidatos com grau de surdez acentuada à surdez moderada;

- 2 correspondem ao nível de encarregado de logística e aceitam candidatos de grau de surdez moderada;

- 1 correspondeu ao nível de supervisor de logística, aceitando candidatos com grau de surdez acentuada, surdez moderada, surdez severa e surdez profunda.

Verificou-se que apenas 3 dos anúncios encontrados descreviam a inserção de surdos com surdez severa, assim, é possível observar que as empresas não estão devidamente preparadas para receber um surdo usuário de Libras.

A partir dos resultados dessa busca, comprova-se que há mercado de trabalho na logística para surdos, no entanto, conforme Lino e Wellichan (2019), em sua maioria são "[...] atividades simples e repetitivas, com baixo grau de mobilidade [...]", se fazem valer ao afirmarem que as funções disponíveis, em maioria, são para cargos de complexibilidade menor como auxiliar e operador.

Como apontado no estudo de Lino e Wellichan (2019, p. 59), “outro desafio é a oportunidade para a pessoa surda alcançar a promoção para um cargo melhor, de maior responsabilidade ou até mesmo de seu interesse". Considerando a baixa profissionalização e formação do candidato e a dificuldade de um processo inclusivo nas empresas, tende-se a afastar as possibilidades de eventuais promoções.

\section{CONSIDERAÇÕES FINAIS}

Conforme mencionado na literatura, a adequação ao ambiente de trabalho é peça chave para a inclusão do surdo no meio organizacional. O objetivo inicial do projeto visava identificar o mercado de trabalho para profissionais surdos na área de logística e após estudos aprofundados de bibliografias, identificamos primeiramente que o surdo é amparado pela lei, não só no âmbito profissional, como pessoal, educacional e de lazer. O desafio enfrentado pelo surdo começa logo em sua infância no meio escolar. A falta de estrutura educacional de formação e profissionalização, de modo a conduzi-lo de uma forma mais inclusiva ao mercado de trabalho ainda é uma lacuna. Isso se reflete, por exemplo, no número de surdos que ingressam e terminam o curso superior. Dessa forma, a admissão de pessoas surdas, no campo 
da logística, não implica apenas cumprir o que a lei de cotas determina, mas requer diversas mudanças, entre elas, as atitudes das pessoas que irão empregá-las e daqueles que farão parte do seu convívio no ambiente de trabalho.

Ao considerar a necessidade da contratação de surdo no mercado de trabalho logístico e mediante a realidade empresarial, surge a necessidade de um olhar atento para as demandas dessa população no processo de inserção no trabalho que possibilita a qualidade de vida, nos quais se incluem: capacitação dos colaboradores para a aprendizagem da Libras e a colocação de intérprete da Libras para garantir a igualdade de acesso à informação entre surdos eu ouvintes.

Os resultados deste estudo mostram que a maioria das vagas disponibilizadas a surdos na área de logística são de cargos operacionais e grande parte dos anúncios são destinados a candidatos que possuem grau de perda auditiva suave e moderada. Tomados em conjunto, tais resultados mostram que as empresas contratantes não estão aptas para receber um Surdo sinalizador, que tenha como primeira língua a Libras. Nesse ponto, identificamos a importância e necessidade de abranger o ensino de Libras não só aos surdos, mas aos ouvintes também.

Espera-se que esse trabalho possa servir como norteador e provocador para futuros estudos sobre a inserção do surdo no mercado de trabalho e leve ao setor de logística uma nova visão da equalização de oportunidades entre surdos e ouvintes nessa área, apesar dessa ação contrastar com incertezas, medos, falta de conhecimentos e preconceitos.

Despertado o interesse pela referida inserção na área logística, espera-se que o profissional surdo possa reter oportunidades de crescimento além dos cargos de complexidade mais baixa. Para tal, ressalta-se a necessidade de desenvolvimento educacional e da profissionalização, tanto de surdos quanto de ouvintes, num movimento de respeito, aceitação e convivência com às diferenças e singularidades humanas.

\section{REFERÊNCIAS}

ATUNES, Maria de Fátima Nunes; ARCARI, Inedio; PURIFICAÇÃO, Marcelo Máximo. Reflexão sobre a inclusão do surdo no mercado de trabalho. Disponível em: https://doi.org/10.37444/issn-2594-5343.v4i3.325. Acesso em: 22 abr. 2021.

BÍBLIA, A. T. Gênesis. In: BÍBLIA. A Bíblia Sagrada: O velho e o novo testamentos. Tradução: João Ferreira de Almeida. São Paulo: Sociedade Bíblica do Brasil, 1996. 
BIEGING, Patrícia; BUSARELLO, Raul Inácio; ULBRICHT, Vania Ribas (org.). Mídia e Educação: novos olhares para a aprendizagem sem fronteira. 1a ed. São Paulo/SP: Pimenta Cultural, 2013.

BORGES, Rosângela Lopes; et al. Inserção e permanência de surdos no mundo do trabalho: estudo exploratório em empresas de um município do centro-oeste goiano. Disponível em: https://doi.org/10.5965/1984317816012020193. Acesso em: 26 abr. 2021.

BRASIL. Associação Nacional de Medicina do Trabalho - ANAMT. A inclusão de pessoas com deficiente no Mercado de trabalho. Disponível em:

http://www.anamt.org.br/site/upload_arquivos/sugestoes_de_leitura_17122013112940533 424.pdf. Acesso em 28 abr. 2021.

BRASIL. [Constituição (1988)]. Constituição da República Federativa do Brasil de 1988. Brasíl ia, DF: Presidência da República, [2016]. Disponível em: http://www.planalto.gov.br/ccivil_0 3/Constituicao/Constituiçao.htm. Acesso em: 29 mar. 2021.

BRASIL. Lei n. 10.436, de 24 de abril de 2002. Dispõe sobre a Língua Brasileira de Sinais Libras e dá outras providências. Brasília, DF: Presidência da República, [2002]. Brasília. Disponível em: http://www.planalto.gov.br/ccivil_03/leis/2002//10436.htm. Acesso em: 21 mar. 2021.

BRASIL. Lei n. 13.146, de 6 de julho de 2015. Institui a Lei Brasileira de Inclusão da Pessoa com Deficiência (Estatuto da Pessoa com Deficiência). Brasília, DF: Presidência da República [2015]. Brasília. Disponível em: http://www.planalto.gov.br/ccivil_03/_ato20152018/2015/lei/l13146.htm. Acesso em: 29 mar. 2021.

BRASIL. Lei n. 13.409, de 28 de dezembro de 2016. Altera a Lei $n=12.711$, de 29 de agosto de 2012, para dispor sobre a reserva de vagas para pessoas com deficiência nos cursos técnico de nível médio e superior das instituições federais de ensino. Brasília, DF: Presidência da República, [2016]. Brasília. Disponível em:

http://www.planalto.gov.br/ccivil_03/_ato2015-2018/2016/lei/I13409.htm. Acesso em: 22 mar. 2021.

BRASIL. Lei n. 8.213, de 24 de julho de 1991. Dispõe sobre os Planos de Benefícios da Previdência Social e dá outras providências. Brasília, DF: Presidência da República, [1991]. Brasília. Disponível em: http://www.planalto.gov.br/ccivil_03/leis/l8213cons.htm. Acesso em: 21 mar. 2021.

BRASIL. Lei n. 9.394, de 20 de dezembro de 1996. Estabelece as diretrizes e bases da educação nacional. Brasília, DF: Presidência da República, [1996]. Brasília. Disponível em: http://www.planalto.gov.br/ccivil_03/leis/19394.htm. Acesso em: 21 mar. 2021.

BRASIL. Ministério da Educação e Cultura. Declaração de Salamanca. Brasília, DF: 1994. Disponível em: http://portal.mec.gov.br/seesp/arquivos/pdf/salamanca.pdf. Acesso em: 20 mar. 2021. 
CHOI, Daniel et al. Libras. 1a ed. São Paulo/SP: Pearson Prentice Hall, 2011.

FERNANDES, Sueli; MOREIRA, Laura Ceretta. Políticas de educação bilíngue para estudantes surdos: contribuições ao letramento acadêmico no ensino superior. Disponível em: https://doi.org/10.1590/0104-4060.51048. Acesso em: 2 abr. 2021.

FRANCO, Esdras da Silva. A teoria da carga cognitiva: Pré-conhecimento e Redução da atenção dividida do ensino de surdos nos processos de eletrização. Disponível em: http://www1.fisica.org.br/mnpef/sites/default/files/dissertacaoarquivo/polo-37dissertacao-esdras.pdf. Acesso em 28 abr. 2021.

GESSER, Audrei. LIBRAS? Que língua é essa?: crenças e preconceitos em torno da língua de sinais e da realidade surda. 1ạ ed. São Paulo: Parábola Editorial, 2009.

GIL, Antônio Carlos. Como elaborar projetos de Pesquisa. 4ạ ed. São Paulo: Atlas, 2002.

GRANT, David B. Gestão de Logística e Cadeia de Suprimentos. 1ạ ed. São Paulo: Saraiva, 2013.

LINO, Carla Cristine Tescaro Santos. 0 atendimento aos alunos surdos matriculados em uma escola pública estadual. Disponível em: https://repositorio.ufsc.br/handle/123456789/ 190836. Acesso em: 6 mai. 2021.

LINO, Carla Cristine Tescaro Santos; WELLICHAN, Danielle da Silva Pinheiro. 0 mercado de trabalho diante da deficiência: estudo de caso de uma repositora de mercadorias surda em uma loja de departamentos. Disponível em: https://doi.org/10.36311/2358-

8845.2019.v6n2.08.p109. Acesso em: 25 abr. 2021.

LOXE, Edson Gomes et.al. A inclusão do Surdo no Mercado de Trabalho Formal. Disponível em: https://www.researchgate.net/publication/334491365_A_Inclusao_do_Surdo_no_Mer cado_de_Trabalho_Formal_The_Inclusion_of_the_Deaf_in_the_Formal_Brazilian_LaborMar ket. Acesso em: 2 abr. 2021.

MACHADO, Ralph. Proposta altera regras para reabilitação profissional e contratação de pessoa com deficiência. Agência Câmara de Notícias, Brasília, 02 set. 2019. Disponível em: https://www.camara.leg.br/noticias/620630-proposta-altera-regras-para-reabilitacaoprofissional-e-contratacao-de-pessoa-com-deficiencia/. Acesso em: 01 mai. 2021.

RAIS - Relatório Anual de Informações Sociais. EVOLUÇÃO DA DISTRIBUIÇÃO DO ESTOQUE DE EMPREGOS FORMAIS POR TIPO DE DEFICIÊNCIA - 2010 A 2019. Disponível em: http://pdet.mte.gov.br/rais. Acesso em: 25 abr. 2021.

SALGADO, Tarcísio Tito. Logística: práticas, técnicas e processos de melhoria. $3 \stackrel{a}{\text { a ed. São }}$ Paulo: Editora Senac, 2019. 
SKLIAR, Carlos. Uma perspectiva sócio-histórica sobre a psicologia e a educação de surdos. (In: SKLIAR, Carlos Org.). Educação e exclusão: abordagens sócio-antropológicas em educação especial. Porto Alegre: Mediação: 1997.

VIEIRA, Claudia Regina; KUMADA, Kate Mamhy Oliveira; MARTINS, Sandra Eli Sartoreto de Oliveira. Acessibilidade em Libras no exame vestibular para surdos. Disponível em: https://doi.org/10.36311/2358-8845.2018.v5n1.02.p13. Acesso em: 2 abr. 2021.

WEBER, Max. A Ética Protestante e o Espírito do Capitalismo. 1a ed. Brasil: Edipro, 2020.

“Os autores declaram estar cientes quanto a responsabilidade pelo conteúdo do artigo." 